\title{
Epidemiological study on human and canine leptospirosis in Central and North Kerala
}

\author{
Manju Soman, V. Jayaprakasan and M. Mini \\ Department of Veterinary Microbiology, College of Veterinary and Animal Sciences, Mannuthy, Thrissur, Kerala, India. \\ Corresponding author: Dr. Manju Soman, e-mail: manjuso1993@gmail.com, VJ: jayaprakasanv@yahoo.com; \\ MM: drmmini@yahoo.co.in \\ Received: 23-06-2014, Revised: 29-08-2014, Accepted: 01-09-2014, Published online: 05-10-2014
}

doi: 10.14202/vetworld.2014.759-764. How to cite this article: Soman M, Jayaprakasan V, Mini M (2014) Epidemiological study on human and canine leptospirosis in Central and North Kerala, Veterinary World 7(10):759-764.

\begin{abstract}
Aim: The aim was to study the epidemiology of human and animal leptospirosis in Central and Northern Kerala, by isolation techniques and serology.

Materials and Methods: Kidney tissues from 35 rodents (11 bandicoots and 24 rats), autopsy specimens from two canines, blood from 15 canines and 30 human beings were subjected to isolation trials for Leptospira. Sera from these animals and human beings were screened for leptospiral antibodies by microscopic agglutination test (MAT).

Results: Leptospira could be isolated from human blood as well as from rodent kidney tissues. The MAT could detect the presence of leptospiral antibodies in $54.54 \%$ of human sera, $36.36 \%$ of dog sera and $21.42 \%$ of rodent sera. Pomona and Australis were the most predominant serovars detected in man, dog, and rodents. Tentative serotyping of the isolates by MAT revealed its identity as Leptospira interrogans serovar Pomona.
\end{abstract}

Conclusion: Detection of common serovars of Leptospira in man and animals by serology as well as isolation reiterates the major role played by animals in the epidemiology of human leptospirosis.

Keywords: canine, epidemiology, human, isolation, leptospirosis, microscopic agglutination test, rodent.

\section{I ntroduction}

Kerala has been witnessing yearly epidemics of leptospirosis in animals and man for the past few decades which have resulted in heavy loss of human and animal lives. As per Antony et al [1], 1523 confirmed cases of human leptospirosis have been reported from a tertiary hospital in Kerala during the period from January 2005 to December 2009, of which 63 had died.

Even though rapid diagnostic techniques have ensured early treatment and cure for the disease, efforts to prevent and control the disease have been unsuccessful. Leptospirosis is one of the most studied zoonotic diseases and the role of animals in the maintenance, propagation, and dissemination of the disease has been widely investigated [2,3]. Rodents are the primary source of leptospiral infection, which can transmit the disease directly to human beings or use a carrier host (domestic animals) for dissemination of the organism. Isolation is the most confirmatory test in the diagnosis of any microbial infection.

The present study aims to show the reservoir status of rodents, the carrier status of animals, and the end host status of human beings, in the epidemiology of human and animal leptospirosis, by isolation and serology.

Copyright: The authors. This article is an open access article licensed under the terms of the Creative Commons Attributin License (http:// creative commons.org/licenses/by/2.0) which permits unrestricted use, distribution and reproduction in any medium, provided the work is properly cited.

\section{Materials and Methods}

Ethical approval

All the procedures have been carried out in accordance with the guidelines laid down by the Institutional Ethics Committee and in accordance with local laws and regulations.

Isolation was tried from kidney tissues and urine samples of rodents captured from the premises of cattle farms and households in central and northern Kerala. Blood samples from clinical cases of human and canine leptospirosis and liver and kidney tissues of autopsied canines presented at hospitals in these regions were subjected to isolation trials in Fletcher's semisolid media with $10 \%$ hemolyzed rabbit sera with and without 5-fluorouracil and EMJH albumin semisolid media. Rodents were anesthetized with chloroform and opened under sterile conditions. Tiny portions of the kidney, collected by puncturing with finely drawn Pasteur pipettes, were inoculated into media tubes and serially diluted into three tubes. The animals were continuously monitored for depth of anesthesia and supplemented with anesthetic as and when required. Liver and kidney tissues from autopsied canines were also collected and inoculated in the same manner. Two drops of whole blood from canines and human beings were inoculated into the test tubes containing the media, at bedside, in the above-mentioned manner.

\section{Serotyping of isolates}

All the six isolates were sent for serotyping at National Leptospirosis Reference Center, Port Blair. 


\section{Serology}

Microscopic agglutination test (MAT)

Sera from 121 canines, 42 rodents, and 154 human beings were subjected to MAT as per Faine [4] with minor modification. A battery of nine pathogenic reference serovars viz., Leptospira interrogans serovars Australis, Canicola, Grippotyphosa, Icterohaemorrhagiae, Pomona, Pyrogenes, Hardjo, Tarassovi, and nonpathogenic Patoc I strain of $L$. biflexa serovar Patoc procured from National Reference Center, Port Blair was used as antigen in MAT. Five to ten day old cultures of the reference strains grown in EMJH liquid media with a density of approximately $2 \times 10^{8}$ leptospires $/ \mathrm{ml}$ of media was used as antigen.

\section{Tentative serotyping of isolates}

The isolates were serotyped by MAT using those field sera that had presented the highest titers to individual reference serovars of Leptospira.

\section{Results}

I solation

Leptospira could be isolated from five rodents in Fletcher's semi-solid media of which, three were from bandicoots designated as BT, M64 and R6, respectively, and two were from rats designated as R13 and M63. Leptospira could also be isolated from one human patient (designated as 289) with severe hepatorenal complications. The isolates BT, M63, and 289 were isolated following 18 days of incubation whereas R6, M64, and R13 were isolated following 60, eight and 34 days of incubation, respectively. Kidney and liver tissues of an autopsied dog, cultured in Fletcher's media, revealed leptospiral growth which failed to grow in subsequent cultures.

\section{Serotyping of isolates}

Of the six isolates that were sent for serotyping at National Leptospirosis Reference Center, Port Blaire, two were serotyped as belonging to serogroup Autumnalis.

\section{Serology}

MAT

A titer of 1:80 and above was considered as positive in dog and human sera whereas a titer of
1:20 [5] was taken as positive in rodent. In rodents, of the 42 samples tested, nine (21.42\%) were positive for leptospiral antibodies, with four of the positive (44.4\%) having antibody titers to Pomona and two $(22.22 \%)$ each for Icterohemorragiae and Australis (Table-1). In dogs, out of the 121 samples tested, 44 (36.36\%) were positive for antibodies to Leptospira. Of these 17 (38.63\%) were positive to serovar Pomona, 16 (36.36\%) were positive to Australis and two were mixed equals (Table-2). In human beings, out of the 154 samples tested, 84 (54.54\%) were positive for leptospiral antibodies with Australis detected in 36 (42.85\%) and Pomona in 24 (28.57\%) sera samples. Two sera were mixed equals (Table-3). The highest titers detected were 1:5120 (to Pomona) in dog, 1:20480 (to Pomona) in rodent and 1:20480 (to Australis) in human beings. The MAT titers are presented in Tables 1-3.

\section{Tentative serotyping of isolates}

Of the six isolates, only four (M64, R13, BT, and 289) grew to the required concentration (to be used as antigen in MAT), in the EMJH liquid media. These were tested against MAT positive sera which had shown high titers to serovars Australis (1:20480), Pomona (1:20480), Grippotyphosa $(1: 10240)$ and Hardjo (1:20480). The isolates 289, BT, and M64 were tentatively serotyped as belonging to serogroup Pomona while R13 was detected as belonging to Australis (Tables 4 and 5).

\section{Discussion}

The present study was carried out to assess the role of canines and rodents in the epidemiology of human leptospirosis, by attempting to isolate Leptospira from rodents as well as human beings and identifying the common serovars infecting animals and man by MAT. Leptospira could be isolated from kidney tissues of five rodents. Isolation of leptospires from rodents have been reported by several authors [6,7]. Isolation of Leptospira from rodents confirmed the reservoir status of these animals in this region. Of the five isolates, three were from bandicoots and two from rats. Bandicoots and rats are reported to be the

Table-1: MAT titres to leptospiral serovars in rodent sera.

\begin{tabular}{|c|c|c|c|c|c|c|c|c|c|}
\hline $\begin{array}{l}\text { Serum } \\
\text { no. }\end{array}$ & Australis & Canicola & $\begin{array}{l}\text { Grippo- } \\
\text { typhosa }\end{array}$ & $\begin{array}{c}\text { I cterohaemorr- } \\
\text { hagiae }\end{array}$ & Pyrogenes & Sejroe & Pomona & Tarassovi & Patoc \\
\hline 1. & $-2 *$ & & & & & & & & \\
\hline 2. & & & & & & & 9* & & 8 \\
\hline 3. & 2 & & & & & & $5 *$ & & \\
\hline 4. & & & & $1 *$ & & & & & \\
\hline 5. & & & & & & & 1* & & \\
\hline 6. & 1 & & & & & & $9 *$ & & 6 \\
\hline 7. & & & & $-1 *$ & & & & & \\
\hline 8. & & $-2 *$ & & & & & & & \\
\hline 9. & $1 *$ & & & & & & & & \\
\hline Total & 2 & 1 & & 2 & & & 4 & & \\
\hline
\end{tabular}

Serum No. 2- Bandicoot (BT), Serum No. 5 - Bandicoot (R6), Serum No. 1, 3, 4, 6, 7, 8, 9 - Rat, *- Serogroup reacting at highest titre presumed to be the infecting one, $-2-1: 20 ;-1-1: 40 ; 1-1: 80 ; 2-1: 160 ; 3-1: 320 ; 4-1: 640$; 5 - 1: 1280; 6 - 1: 2560; 7 - 1: 5120; 8 - 1: 10240; 9 - 1: 20480 
Table-2: MAT titres to leptospiral serovars in dog sera.

\begin{tabular}{|c|c|c|c|c|c|c|c|c|c|}
\hline $\begin{array}{l}\text { Serum } \\
\text { no. }\end{array}$ & Australis & Canicola & $\begin{array}{l}\text { Grippo- } \\
\text { typhosa }\end{array}$ & $\begin{array}{l}\text { I cterohaemorr- } \\
\text { hagiae }\end{array}$ & Pyrogenes & Sejroe & Pomona & Tarassovi & Patoc \\
\hline 1. & & 1* & & & & & & & \\
\hline 2. & & & & & & & 5* & & 4 \\
\hline 3. & & & 1 & 3* & & & 1 & & 1 \\
\hline 4. & & & & & & & $1 *$ & & 1 \\
\hline 5. & $1^{*}$ & & & & & & 1 & & 1 \\
\hline 6. & 1 & 1 & 1 & & & & 1 & & 1 \\
\hline 7. & $6 *$ & & 2 & & & & 4 & & \\
\hline 8. & & & & & & & 3* & & \\
\hline 9. & 6* & & & & & & & & \\
\hline 10. & 2* & & & & & & & & \\
\hline 11. & $7 *$ & 1 & 3 & 2 & & & 3 & & 3 \\
\hline 12. & & & & & & & 3* & & 2 \\
\hline 13. & & & & & & & $2 *$ & & 2 \\
\hline 14. & $4 *$ & & & & & & & & 2 \\
\hline 15. & $2 *$ & & & & & & & & \\
\hline 16. & & & 4 & & & & $7 *$ & & 4 \\
\hline 17. & & & & & & & 2 & & $3 *$ \\
\hline 18. & 1 & 1 & & & & & & & \\
\hline 19. & & & & & & & $5^{*}$ & & 4 \\
\hline 20. & & $1 *$ & & & & & & & \\
\hline 21. & & & & & & & $1 *$ & & 1 \\
\hline 22. & & & 1 & $3 *$ & & & & & \\
\hline 23. & 1 & 1 & 1 & & & & $2 *$ & & 1 \\
\hline 24. & & & 4 & & & & $7 *$ & & 4 \\
\hline 25. & & & & & & & $3 *$ & & \\
\hline 26. & $2 *$ & & & & & & 1 & & 1 \\
\hline 27. & 2* & & & & & & & & \\
\hline 28. & 6* & & & & & & & & \\
\hline 29. & $4 *$ & & & & & & & & 2 \\
\hline 30. & & & & & & & 3* & & 3 \\
\hline 31. & 7* & 1 & 3 & 2 & & & 3 & & 2 \\
\hline 32. & $2 *$ & & & & & & & & \\
\hline 33. & $6 *$ & & 2 & & & & 4 & & \\
\hline 34. & & & & & & & 2 & & $3 *$ \\
\hline 35. & & & & & & & $2 *$ & & \\
\hline 36. & 1 & $2 *$ & & & & & & & \\
\hline 37. & $3^{*}$ & & & & & & & & \\
\hline 38. & & & & & & & $2 *$ & & 1 \\
\hline 39. & & & 6* & & & & 2 & & 2 \\
\hline 40. & & & & & & & $2^{*}$ & & 2 \\
\hline 41. & 2* & & 1 & & & & 1 & & 1 \\
\hline 42. & 1 & & & & & & $2 *$ & & 1 \\
\hline 43. & 3 & & & & & & $4 *$ & & \\
\hline 44. & 1 & 1 & & 2* & & & & & \\
\hline Total & 16 & 3 & 1 & 3 & & & 17 & & 2 \\
\hline
\end{tabular}

Mixed Equals in dogs - Canicola and Australis-1, Grippotyphosa, Australis and Pomona-1

most important reservoir hosts of Leptospira among rodent species [8,9]. Leptospira could be isolated from one human patient in Fletcher's semisolid media with $10 \%$ rabbit sera. Fletcher's and Korthoff's media is reported to be superior to EMJH media for isolation of leptospires from human blood [10]. The inability to isolate Leptospira from other infected human beings could be attributed to administration of antibiotics by local practitioners before the patients were referred to the hospitals [11]. Kidney and liver tissues of an autopsied dog, cultured in Fletcher's media, revealed leptospiral growth which failed to grow in subsequent subcultures. In this study, MAT detected a prevalence of $21.42 \%$ in rodents which is in correlation with the results of the study conducted by [3]. The bandicoots and two rats, from which M64, M63, and R13 were isolated, tested serologically negative by MAT. This phenomenon of isolation positive, serology negative rodents have been observed repeatedly by many authors [12,13]. Rodents are susceptible to acute infection only in the early days of their life. Later, the immune system develops, and surviving ones become resistant to further infection [4]. This could be a probable reason for the low levels of antibodies detected in rodents. As the leptospires get lodged in the renal tubules of the rodents, rodent urine becomes a source of leptospiral infection in grazing animals like cattle, which in turn contribute to infection in human beings [14]. The serum sample from the culture positive human patient (isolate no. 289), tested negative by MAT. The absence of antibodies to Leptospira in the serum of the patient from whom isolation was 
Table-3: MAT titres to leptospiral serovars in human beings.

\begin{tabular}{|c|c|c|c|c|c|c|c|c|c|}
\hline $\begin{array}{l}\text { Serum } \\
\text { no. }\end{array}$ & Australis & Canicola & $\begin{array}{l}\text { Grippo- } \\
\text { typhosa }\end{array}$ & $\begin{array}{c}\text { I cterohaemorr- } \\
\text { hagiae }\end{array}$ & Pyrogenes & Sejroe & Pomona & Tarassovi & Patoc \\
\hline 1. & 2 & & & & & & 7* & 2 & 6 \\
\hline 2. & $4 *$ & & & & & & 2 & & 3 \\
\hline 3. & 4 & & & & 2 & & $6 *$ & 2 & 5 \\
\hline 4. & 4 & & 4 & & & & 4 & & $5 *$ \\
\hline 5. & 4 & & & & & & 8* & & 6 \\
\hline 6. & $1 *$ & & & & & & & & \\
\hline 7. & 3 & & & & & & 5* & 1 & 4 \\
\hline 8. & 4* & & & & & & 1 & & \\
\hline 9. & & $1 *$ & & & & & & & \\
\hline 10. & 2 & & 8 & 6 & & & 9* & & \\
\hline 11. & 1 & 1 & & & 1 & & 4* & 1 & 3 \\
\hline 12. & 1 & & & & $2 *$ & & 1 & & \\
\hline 13. & $2 *$ & & & & & & 1 & & 1 \\
\hline 14. & & & & & & & 3* & & \\
\hline 15. & & & 1 & 6 & & & $3 *$ & & 2 \\
\hline 16. & 5 & & & & & & 7* & & 6 \\
\hline 17. & $1 *$ & & & & & & & & \\
\hline 18. & 2* & & & & & & & & \\
\hline 19. & $1 *$ & & & & & & & & \\
\hline 20. & & & & $1 *$ & $4 *$ & & & & \\
\hline 21. & & & & & & & & & 3 \\
\hline 22. & & & & & & & & & $1 *$ \\
\hline 23. & & 1 & & 1 & & & & & \\
\hline 24. & $1 *$ & & & & & & & & \\
\hline 25. & $6 *$ & & 3 & & & & 3 & & 5 \\
\hline 26. & $1 *$ & & & & & & & & \\
\hline 27. & 9* & 5 & & 3 & & & 6 & & 5 \\
\hline 28. & $2 *$ & & & & & & & & \\
\hline 29. & 3 & & & & & & $4 *$ & & \\
\hline 30. & & & & $1 *$ & & & & & \\
\hline 31. & 2* & & & & & & & & \\
\hline 32. & 4 & & & & 2 & & 6* & 2 & 5 \\
\hline 33. & & & & $1 *$ & & & & & \\
\hline 34. & 4 & & & & & & 8* & & 6 \\
\hline 35. & $1 *$ & & & & & & & & \\
\hline 36. & 3 & & & & & & 5* & 1 & 4 \\
\hline 37. & & 1 & & 1 & & & & & \\
\hline 38. & 9* & 5 & & 2 & & & 6 & & 6 \\
\hline 39. & & $1 *$ & & & & & & & \\
\hline 40. & 1 & 1 & & & & & 4* & 1 & 3 \\
\hline 41. & $1 *$ & & & $1 *$ & & & & & \\
\hline \multicolumn{10}{|l|}{42.} \\
\hline 43. & $9 *$ & & & & & & 5 & 2 & 5 \\
\hline 44. & $2 *$ & & & & & & 1 & & \\
\hline 45. & & 1 & & & & & & & $5 *$ \\
\hline 46. & & & 1 & & & & 3* & & 2 \\
\hline 47. & & & 1 & & & & 2* & & \\
\hline 48. & & 1 & 1 & & & & & & 5* \\
\hline 49. & 7* & & & & & & 6 & & 6 \\
\hline 50. & 8* & & & & 1 & & 6 & & 7 \\
\hline 51. & & & & & & & 1 & & $2 *$ \\
\hline 52. & $9 *$ & & & & & & 5 & 2 & 5 \\
\hline 53. & 2 & & 4* & & & & 2 & & 2 \\
\hline 54. & $1 *$ & & & & & & & & \\
\hline 55. & $2 *$ & & 1 & & & & 1 & & 2 \\
\hline 56. & & & $4 *$ & & 1 & & 3 & & 4 \\
\hline 57. & 3 & 2 & & & 3 & & $5 *$ & 3 & 2 \\
\hline 58. & $1 *$ & & & & & & & & \\
\hline 59. & 4* & & & & & & 3 & & 3 \\
\hline 60. & $1 *$ & & & & & & & & \\
\hline 61. & 1 & & & & $4 *$ & & & & 3 \\
\hline 62. & $4 *$ & 1 & & & & & 2 & & 3 \\
\hline 63. & & & 2 & & & & $5^{*}$ & & \\
\hline 64. & 4 & & 4 & & & & 4 & & $5 *$ \\
\hline 65. & 7* & & & & & & 5 & & 5 \\
\hline 66. & 6* & & 3 & & & & 3 & & 5 \\
\hline
\end{tabular}


Table-3: Contd...

\begin{tabular}{|c|c|c|c|c|c|c|c|c|c|}
\hline $\begin{array}{l}\text { Serum } \\
\text { no. }\end{array}$ & Australis & Canicola & $\begin{array}{l}\text { Grippo- } \\
\text { typhosa }\end{array}$ & $\begin{array}{c}\text { I cterohaemorr- } \\
\text { hagiae }\end{array}$ & Pyrogenes & Sejroe & Pomona & Tarassovi & Patoc \\
\hline 67. & $1^{*}$ & & & & & & & & \\
\hline 68. & $8^{*}$ & & & & 2 & & 6 & & 7 \\
\hline 69. & $4 *$ & & & & & & & & 2 \\
\hline 70. & & & & & & & 1 & & $2 *$ \\
\hline 71. & 2 & & 8 & 7 & & & 9* & & \\
\hline 72. & 2 & & 4* & & & & 2 & & \\
\hline 73. & 2* & & & & & & & & 2 \\
\hline 74. & 1 & & & & 2* & & 1 & & \\
\hline 75. & 2* & & 1 & & & & 1 & & 2 \\
\hline 76. & & & & & & & 3* & & \\
\hline 77. & & & $4 *$ & & 1 & & 3 & & 4 \\
\hline 78. & 3 & & & & & & $4 *$ & & \\
\hline 79. & 3 & 2 & & & 3 & & $5^{*}$ & 3 & 2 \\
\hline 80. & 5 & & & 6 & & & 7* & & 6 \\
\hline 81. & $4^{*}$ & & & & & & 3 & & 3 \\
\hline 82. & & & & & & & & & $1 *$ \\
\hline 83. & 2 & & & & & & $6 *$ & 2 & 6 \\
\hline 84. & $2 *$ & & & & & & & & 1 \\
\hline 85. & 36 & 2 & 4 & 4 & 4 & & 24 & & 8 \\
\hline
\end{tabular}

Mixed equals in man- Icterohaemorrhagiae and Canicola- 2.

Table-4: MAT titres of positive sera to reference serovars of Leptospira.

\begin{tabular}{|c|c|c|c|c|c|}
\hline \multirow{2}{*}{$\begin{array}{l}\text { Reference serovars } \\
\text { of Leptospira }\end{array}$} & \multicolumn{5}{|c|}{ Positive test sera samples having high titres to reference serovars } \\
\hline & 293 & 121 & 576 & $\mathbf{R 9}$ & TB12 \\
\hline Icterohaemorrhiae & $1: 320$ & $1: 5120$ & $1: 2560$ & & \\
\hline Pomona & $1: 2560$ & $1: 20480$ & $1: 5120$ & $1: 80$ & \\
\hline Australis & $1: 20480$ & $1: 160$ & $1: 1280$ & & \\
\hline Patoc & $1: 2560$ & & $1: 2560$ & $1: 80$ & \\
\hline Canicola & $1: 1280$ & & & & \\
\hline Grippotyphosa & & $1: 10240$ & & $1: 2560$ & \\
\hline Hardjo & & & & & $1: 20480$ \\
\hline
\end{tabular}

Table-5: MAT titres of positive test sera to local isolates of Leptospira.

\begin{tabular}{lccccc}
\hline I solate & \multicolumn{5}{c}{$\begin{array}{c}\text { Positive test sera samples having high } \\
\text { titres to reference serovars }\end{array}$} \\
\cline { 2 - 6 } & $\mathbf{2 9 3}$ & $\mathbf{1 2 1}$ & $\mathbf{5 7 6}$ & $\mathbf{R 9}$ & TB12 \\
\hline 289 & $1: 320$ & $1: 1280$ & & & \\
BT & $1: 5120$ & $1: 10240$ & $1: 640$ & & \\
M64 & $1: 640$ & $1: 2560$ & $1: 640$ & $1: 80$ & \\
R13 & $1: 5120$ & & $1: 320$ & & \\
\hline
\end{tabular}

made was paradoxical. However, isolation of leptospires from cattle and human beings without detectable antibody titers has been reported earlier [15]. One of the reasons could be that protective antibodies had not been produced in the patient's body at the time of collection of serum as the serum, for serology, was separated from the same blood which was used for isolation trial.

The results of tentative serotyping suggested that the local isolates belonged to serogroups Pomona and Australis (Tables 1 and 2). The MAT conducted on field sera (Tables 3-5) also revealed Pomona and Australis as the predominant serovars infecting man, animals and rodents. This points at the major role played by domestic and peridomestic animals in the epidemiology of human leptospirosis. The results of serotyping from National Leptospirosis Reference Centre, Port Blair, suggested that two of the isolates belonged to serogroup Autumanalis. As this serovar had not been included as an antigen for MAT in this study, the possibility of Autumanalis being the predominant serovar in the region cannot be ruled out. MAT should ideally be done on paired sera samples, for detection of a fourfold rise in the antibody titer. Since agglutinins to MAT tend to remain in the body for a prolonged period of time following infection, detectable MAT titers may be present even in healthy animals and man. But in an acute infection, MAT titers develop very late in the body usually by the second to fourth week of infection. These two factors may account for the false positive and the false negative results by MAT [16]. In this study, the cutoff titer for MAT in humans and canines were kept at 1: 80 dilutions as per results cited by various authors [16-18].

\section{Conclusion}

Control measures for leptospirosis should begin from rodents, which are the main reservoir hosts of Leptospira, and domestic animals, which are the carrier hosts of the infection. The current study reveals the presence of common leptospiral serovars, Pomona, and Australis, infecting man, animals, and rodents, by 
serology and isolation. Hence this study reiterates the need for a strong and highly detailed control program for leptospirosis in this region, which should begin from the rodents and encompass the domestic animals as well.

\section{Authors' Contributions}

MS carried out the study, drafted and revised the manuscript. VJ designed the experiment and MM participated in scientific discussion. All authors read and approved the final manuscript.

\section{Acknowledgments}

The authors are highly thankful to the Dean, College of Veterinary and Animal Sciences, Mannuthy, for providing facilities and fund for this study. The authors are also thankful to Dr. G. Krishnan Nair, Dr. Koshy John and Dr. E. Nanu for all the help rendered and the National Leptospira Reference Centre, Regional Medical Research Centre, Port Blair, Andaman and Nicobar Islands for providing the reference serovars used in the study.

\section{Competing I nterests} interests.

The authors declare that they have no competing

\section{References}

1. Antony, J., Celine, T.M. and Chacko, M. (2012) Case fatality rate of leptospirosis in a tertiary care hospital in Kerala, in India. Ann. Trop. Med. Public Health, 5(3): 236-239.

2. $\quad$ Parez, J., Brescia, F., Becam, J., Mauron, C. and Goarant, C. (2011) Rodent abundance dynamics and leptospirosis carriage in an area of hyper-endemicity in New Caledonia. PLoS. Negl. Trop. Dis., 5: 10.

3. Patil, D., Dahake, R., Roy, S., Mukherjee, S., Chowdhary, A., and Deshmukh, R. (2014) Prevalence of leptospirosis among dogs and rodents and their possible role in human leptospirosis from Mumbai, India. Indian J. Med. Microbiol., 32: 64.

4. Faine, S. (1982) Guidelines for the control of leptospirosis. Offset Publication No.67. World Health Organization, Geneva, Switzerland. p171.

5. Vanasco, N.B., Lottersberger, J., Sequeira, M.D. and Tarabla, H. (2001) Development and validation of an
ELISA for the detection of leptospire-specific antibodies in rodent. Vet. Microbiol., 82: 321-330.

6. Loffler, SG., Pavan, ME., Vanasco, B., Samartino, L., Suarez, O., Auteri, C., Romero, G., and Brihuega, B. (2014) Genotypes of pathogenic Leptospira spp isolated from rodents in Argentina. Mem. Inst. Oswaldo. Cruz., 109(2): 163-7.

7. Scialfa, E., Bolpe, J., Bardón, JC., Ridao, G., Gentile, J. and Gallicchio, O. (2010) Isolation of Leptospira interrogans from suburban rats in Tandil, buenos aires, Argentina. Rev. Argent. Microbiol., 42(2): 126-8.

8. Pargaonker, V.N. (1957) Rats as carriers of Leptospira. Indian Vet. J., 34: 205-208.

9. Adinarayanan, N., and James, P.C. (1980) Studies on leptospirosis in farm stock and wildlife in Kerala. Indian Vet. J., 57: 496-500.

10. Venugopal, K., Ratnam, S. and Stallman, N.D. (1990) Isolation and identification of leptospires from a human case. Indian J. Comp. Microbiol. Immunol. Infect. Dis., 11: 99-100.

11. Bharadwaj, R., Bal, A.M., Joshi, S.A., Kagal, A., Pol, S.S., Garad, G., Arjunwadkar, V. and Katti, R. (2002). An outbreak of leptospirosis in Mumbai, India. Jpn. J. Infect. Dis., 55: 194-196.

12. Shotts, E.B., Andrews, C.L. and Harvey, T.W. (1975) Leptospirosis in selected wild mammals of the Florida pan handle and South Western Georgia. J. Am. Vet. Med. Assoc., 167: 587-589.

13. Thiermann, A.B. (1977) Incidence of leptospirosis in the detroit rat population. Am. J. Trop. Med. Hyg., 26: 970-973.

14. Natarajaseenivasan, K. and Ratnam, S. (1997) Seroprevalence of leptospiral infection in an agricultural based village in Tamil Nadu. Cheiron., 26: 80-83.

15. Anderson, J.F., Miller, D.A., Post, J.E., Johnson, R.C., Magmarelli, L.A. and Andreadis, T.G. (1993) Isolation of Leptospira interrogans serovar Grippotyphosa from the skin of a dog. J. Am. Vet. Med. Assoc., 203: 1550-1551.

16. Vijayachari, P., Sugunan, A.P. and Sehgal, S.C. (2001) Evaluation of microscopic agglutination test as a diagnostic tool during acute stage of leptospirosis in high \& low endemic areas. Indian J. Med. Res. 114: 99-106.

17. Arumugam, G, Jacob, S.M, Anitha, D. and Rajappa, S.M. (2011) Occurrence of leptospirosis among suspected cases in Chennai, Tamil Nadu. Indian J. Pathol. Microbiol., 54: 100-2.

18. Panwala, T., Mulla, S. and Patel, P. (2011) Seroprevalence of leptospirosis in South Gujarat region by evaluating the two rapid commercial diagnostic kits against the mat test for detection of antibodies to Leptospira interrogans. Natl. J. Community Med., 2(1): 64-70. 